\title{
UNIVERSITYOF
}

FORWARD

THINKING

WESTMINSTER用

WestminsterResearch

http://www.westminster.ac.uk/westminsterresearch

Perceived barriers and facilitators to female condoms among UK based healthcare professionals

Burton, J., Bedford, R., Graham, C. and Nadarzynski, T.

This is an accepted manuscript of an article published by Taylor \& Francis in the

European Journal of Contraception and Reproductive Health Care,

DOI:10.1080/13625187.2020.1777966.

The final definitive version is available online:

https://dx.doi.org/10.1080/13625187.2020.1777966

(c) 2020 Taylor \& Francis

The WestminsterResearch online digital archive at the University of Westminster aims to make the research output of the University available to a wider audience. Copyright and Moral Rights remain with the authors and/or copyright owners. 
Accepted in The European Journal of Contraception and Reproductive Health Care on 31/05/2020

\section{Title: Perceived barriers and facilitators to female condoms among UK based healthcare} professionals

Jack Burton $^{1}$, Rowena Bedford ${ }^{1}$, Cynthia Graham ${ }^{1} \&$ Tom Nadarzynski ${ }^{2}$

1. Department of Psychology, The University of Southampton, Southampton, UK

2. Social Sciences, The University of Westminster, London, UK

\section{Corresponding author:}

Dr Tom Nadarzynski

School of Social Sciences and Humanities

University of Westminster

115 New Cavendish Street

London W1W 6UW

T.Nadarzynski@westminster.ac.uk 


\begin{abstract}
Objectives: The female condom (FC) is an effective strategy against sexually transmitted infections (STIs) in susceptible women and men who have sex with men. FCs are the only female-initiated dual protection method that protects against both STIs and unintended pregnancy. As healthcare professionals (HCPs) are a key element in the promotion of contraceptive use, it is important to examine attitudes toward FCs among this group. Study participants: 15 male and female HCPs aged between 22-57 years recruited from sexual and reproductive health settings located in Brighton, London, and Glasgow. Sampling method: purposive sampling with targeted advertisements (newsletters and bulletins). Study design: face-to-face and telephone interviews with sexual health HCPs. Main outcome measure: potential barriers and facilitators to FCs in the UK. Data were analysed thematically to identify common views and perspectives. Results: FCs were thought to be unacceptable to most women due to stigma, design, negative visual appeal, insertion difficulties and lack of familiarity. The perceived unavailability and higher cost of FCs, in comparison to male condoms, are major barriers to their use. Conclusions: HCPs are reluctant to promote FCs, often due to the perceived social stigma surrounding FCs. Further education and promotion are needed to increase acceptability and correct usage. Future research needs to explore strategies to increase the acceptability of FCs among women, men who have sex with men and HCPs.
\end{abstract}

Keywords: Female condom, healthcare professionals, barriers, facilitators, qualitative.

Funding: The authors received no specific funding for this work.

Conflict of interest: The authors declare no conflict of interest. 


\section{Introduction}

In the UK, both sexually transmitted infection (STI) and unintended pregnancy rates remain relatively high. In 2017, there were 422,147 diagnoses of STIs made in England (1) and an estimated 862,785 conceptions, of which one-third were reported as unintended (2). Unintended pregnancies and STIs represent an estimated economic burden on the UK's National Health Service (NHS) in excess of $£ 620$ million per year (3). Heterosexual women remain at a higher risk than men of acquiring an STI (4) and by nature assume the sole physical burden of pregnancy (5).

Sexual health promotion is largely focused on the male condom (MC) for STI prevention in both men (6) and women (7), and long-acting reversible contraception (LARC) methods in preventing unintended pregnancy for women (8). However, LARC methods do not protect against STIs (9) and the MC relies on women negotiating correct use with their male partners (10). There is therefore a need for a female-initiated dual protection method.

The female condom (FC), also known as an 'internal condom' or 'femidom', is currently the sole female-initiated dual protection method for STI prevention and contraception (11). This barrier device is fitted inside the vagina (12) and can be inserted up to eight hours before intercourse using one of two flexible rings and covers both internal and external genitalia, proving useful for preventing STIs that are spread primarily via skin contact (e.g. human papillomavirus) (11). FCs have a lower rate of leakage than MCs (13) and can be used both vaginally and anally, broadening their acceptability, in particular for the LGBTQ+ community.

However, the FC remains underutilised (14) and has faced "formidable hurdles owing to significant structural and social barriers" (15). These include a lack of FC production and supply, higher cost compared to the MC, resistance from male partners, negative press, and minimal promotional efforts (11). A descriptive cross-sectional study (16) assessing Ghanaian women aged 15-49 years demonstrated low FC use, with only $48.4 \%$ of the 380 participants aware of FCs. This 
underutilisation may be explained by low FC accessibility and partner resistance, highlighting a gender power imbalance.

Possible advantages of the FC over the MC include comfort, enhanced sexual pleasure, lack of male responsibility, and the promotion of women's sexual agency. (17) For example, in a sample of urban Indian women, the FC was attributed with increased pleasure, the alleviation of stress associated with STI transmission and pregnancy, especially as some male partners were resistant to MC use. (17) However, other women disliked FCs due to decreased pleasure. FCs therefore have potential, but design modifications may be required to improve the women's experience with them.

\section{Healthcare professionals' perceptions of ICs}

Healthcare professionals (HCPs) treat and prevent illness, injury, and physical and mental health problems. The term HCP covers a myriad of job roles, including doctors, nurses, sexual health advisors, social workers, and psychologists. Their role has been posited as a "major missing link" in the body of FC research. (15) HCP's acceptance and endorsement of particular contraceptive methods may be key in service users' uptake of the method, as demonstrated by Steiner et al., who found that having contact with a health professional was the only factor attributed to consistency of birth control usage and the reason for starting contraception (18).

Only a handful of studies have investigated HCP's perceptions of FCs (15). In a qualitative study of 69 semi-structured interviews with HCPs across 5 HIV/STI and pregnancy prevention agencies in New York, sites had zero or a very limited supply of FCs and little knowledge of device insertion. Several HCPs regarded FCs as aesthetically unappealing and structurally problematic (e.g. the inner ring being too hard). HCPs were also unsure as to whether FCs should be targeted for young people or more "high risk" groups such as sex workers. Generalising this study to the wider population of HCPs and their clients may, however, be problematic as only one US city was sampled, with predominantly young low-income black or Hispanic clients at a high risk of HIV/STIs. 
The present study sought to add to the limited evidence on the topic by exploring UK HCP's perceptions of the FC. Studies have suggested that HCP's acceptance and endorsement of particular contraceptive methods may be key in service users' uptake of a method. (18) Study aims included identifying UK HCP's perceptions of the FC and their perceived barriers and facilitators to FC uptake. To the best of our knowledge, the present study was the first to investigate the perceptions of the FC among HCPs in the UK.

\section{Methods}

\section{Design}

A qualitative approach using semi-structured interviews, conducted between March to July 2018, and thematic analysis was used to explore the attitudes of HCPs toward FCs. Ethical approval for this study was obtained by the the University of Southampton Ethics committee (ref: 31205 ).

\section{Recruitment and participants}

Purposive sampling was used to recruit participants. Snowball sampling, a type of purposive sampling, is a non-probability sampling method whereby existing participants recruit future participants from amongst their social or professional networks (19). Snowball sampling has the advantage of creating "dynamic moments where unique social knowledge of an interactional quality can be fruitfully generated" (20). Inclusion criteria included: UK-based HCPs practising in either a sexual or reproductive health setting (e.g. Genitourinary medicine (GUM) clinics, family planning clinics etc.) or general practice (e.g. GP surgery). HCPs were excluded if they were not actively practising, worked in settings other than sexual and reproductive health or general practice, or were based outside of the UK.

Advertisements were distributed via newsletters and bulletins through three UK based sexual health services (Brighton, London, and Glasgow). These advertisements invited potential participants to contribute to a 30-minute interview exploring the attitudes and perspectives of HCPs from GUM clinics, general practitioners and related sexual health settings towards the FC in order to greater 
understand potential barriers and facilitators to FC uptake, and the promotion of the FC to service users. Potential participants were asked to contact the first author directly via email and forward the advert to colleagues working in sexual health. The study advertisement contained an information sheet and online link where participants could record their email address to allow for a telephone interview to be arranged. Both face-to-face and telephone interviews were used for data collection. Telephone interviews were done with participants who were unable to meet in person.

All participants provided informed consent; verbal consent was also obtained prior to interview commencement. The semi-structured interview topic guide (see Table 1) consisted of openended questions to allow for participants' expression of their attitudes and experiences. Questions were based around topics such as the efficacy of the FC, distribution challenges, and HCP FC recommendations. Interviews were audio-recorded and the audio files were stored on a passwordprotected computer. Recordings were transcribed verbatim by the first author and analysed consecutively. Interviews lasted between 10 to 27 minutes.

\section{Data analysis}

The first author (a male postgraduate Health Psychology student) collected and analysed the data, using Braun and Clarke's method of thematic analysis. (21) Each transcript was read and reread, coded, and grouped into themes (based on the conceptual similarity of the codes). For example, the theme 'Perceived barriers to FC uptake' (see Table 2) included the codes 'availability', 'acceptability' and 'cost' of the FC. Collecting and analysing data continued until theoretical saturation was reached, in this case when coding of the fifteenth participant had been completed. To ensure consistency of analysis, the themes were discussed with the co-authors, who also reviewed the original transcripts.

\section{Results}

Participants were aged between 22-57 years (mean=38, median=37). Fifteen participants took part in the study; $73 \%$ of the sample (11) were women and $27 \%$ of the sample (4) were men. All 
participants held professional roles in sexual health or general practice settings including: sexual health nurse (4), sexual health advisor (3), speciality doctor in sexual health (3), consultant doctor in sexual health (2), trainee GP (2), and sexual health technician (1). Six interviews were conducted face-to-face, with the remaining nine conducted via telephone. Years of professional sexual health experience ranged from 1-22 years (mean=8.8, median=10). Participants were based in sexual and reproductive health settings in Brighton, London, and Glasgow.

In total, six themes were identified reflecting barriers and facilitators to FCs: 'Acceptability', 'Device limitations and insertion difficulties', 'Availability', 'Cost', 'Education and Promotion', and 'HCP Training'.

\section{Acceptability}

Participants were in agreement that FCs are regarded as an unacceptable barrier method for STI prevention and contraception and there was general disinterest in FCs: “... the user is just not that interested in them..." (age 40, a specialist doctor in sexual health). Some mentioned possible social stigma surrounding FCs, where FCs are 'frowned upon', making them a less acceptable barrier method:

“...it's not exactly the coolest method of contraception, it's kind of like, frowned upon if you're using a female condom..." (age 22, sexual health technician).

One participant suggested that the stigma surrounding FCs may be due to women not wanting “to look like they're 'up for it"” (age 42, sexual health advisor), adding that women in the UK find carrying MCs far more acceptable than carrying FCs. Overall, FCs were perceived as being unacceptable to women.

\section{Device limitations and insertion difficulties}

Comments suggested that the FC design restricted uptake, with FC likened to a "rustling plastic bag" or a "crisp packet". They were viewed as aesthetically and audibly unpleasant, and perceived as potentially "ruining the mood" during a sexual encounter: 
"I suppose they're [FCs] not very attractive to look at and they're quite noisy so, you know, getting one of those condoms out in the middle of having sex can be a bit of an off-putting experience I suppose." (age 46, assistant sexual health advisor).

Some considered the FC's external packaging to be larger than the MC, making the product less discreet: “...the packets of the female condoms are much larger so you can't really take them out discreetly..." (age 37, clinical nurse specialist).

Ease of device insertion was also considered a barrier to FC uptake. For example, when compared to MCs, the FC was regarded as "fiddlier" and impractical “...asking women halfway during a sexual act to open a packet and then sort of, fiddle around putting it inside her, they just look at you as if you're completely crazy..." (age 40, a specialist doctor in sexual health). This may reduce device effectiveness. If not inserted correctly, the penis could "miss" the FC during intercourse and make the device redundant. Additionally, for some populations, such as those lacking dexterity, or those intoxicated, difficulty in FC insertion may be too great to warrant it as a viable option.

\section{Availability}

All participants believed the $\mathrm{FC}$ to be far less available than the $\mathrm{MC}$, often remarking having rarely seen the device in either commercial or healthcare settings. Three participants stated they had never seen an FC in a clinical environment: “...I've never seen anyone using one [FC] in a clinical setting." (age 26, trainee GP). FC availability was perceived to be poor and this was positioned as a barrier to uptake.

\section{Cost}

Most HCPs perceived FCs to be significantly more expensive to manufacture than MCs: “They're [FCs] more expensive to produce too aren't they, so that's probably a factor [in FC uptake]" (age 40, speciality doctor in sexual health). Compared to MCs, FCs were thought to be more expensive for both consumer and company: "They're [FCs] just more expensive than male 
condoms..." (age 57, speciality doctor in sexual health). National MC distribution schemes were mentioned as hindering FC uptake; some participants believed that users would prefer to use freely available MCs than to buy FCs. Whilst some participants perceived price to hinder FC uptake, this was disputed by three participants who argued FC cost was irrelevant to their position as an underutilized method and instead suggested that the issue was more related to product demand: “Well...no. I don't think it's a cost issue, it's a demand issue." (age 33, sexual health advisor).

\section{Education and Promotion}

Participants believed that educating the public (particularly young people) about FCs would act as a stepping stone to greater use of the device: “...one of the main things [to increase FC uptake] would be, shorter-term education targeted campaigns towards young people would be quite useful". (age 37, sexual health consultant). Participants highlighted a need to educate women on correct FC application: "...actually having somebody demonstrate it, exactly how to put it on and everything..." (age 27, trainee GP). A change in healthcare education policy toward the FC was also mentioned, such as including the method in Family Planning Association (FPA) leaflets: “...using the FPA leaflet that's got every single type [of contraception] so that you can unpack what's acceptable for them." (age 33, sexual health advisor), and including FC education in sex and relationships education for young people: “...they need to have a sex and relationships education policy, and... include erm, more information about female condoms..." (age 42, sexual health advisor). Participants mentioned that FCs should be promoted as equal to MCs: “...you've got to talk about a female condom with as much enthusiasm and as much know-how..." (age 37, clinical nurse specialist). FC promotional methods mentioned included sexual health campaigns, school sex education interventions, charities and commercial retailers (such as high street brands), “...in conjunction with somebody like Ann Summers, erm, as an adjunct to their parties, and get people on board like that" (age 33, sexual health advisor). 
Targeted FC promotion towards specific populations was perceived to facilitate increased uptake. Some argued that targeting young people (16-25) would be best as they represent a group at risk of STIs. A couple of participants expressed the importance of familiarizing young people with the FC towards the beginning of their sexual history and believed that doing so would normalize FCs to young people: “...if they know that their friends are using it, ...., then they would know "ah other people at my age are using it as well" (age 42, sexual health advisor). However, some questioned whether young people would want to use the device or be committed to learning correct device insertion. Instead, these HCPs suggested that FC promotion would better serve older women with more sexual and reproductive experience or women who experience difficulty in condom negotiation with male partners.

\section{HCP training}

In general, the FC was perceived to be a somewhat "forgotten method" and participants spoke about the importance of "getting the professionals talking about it [FC]". Some participants thought that "training the trainers" was important to allow HCPs to become comfortable and confident in promoting the FC to service users: "I think maybe re-training staff is key so that they're comfortable and confident to give them [FCs] out." (age 33, sexual health advisor). Two participants suggested that the most efficient way to train HCPs on the FC would be to have either 'education days' or 'refresher sessions' which involve all staff present on a given day: “...the way to go about that is through education days, if you're going to do it in-service, because you should have all the clinicians there at that point." (age 29, sexual health nurse).

Not everyone agreed HCP training would increase FC uptake, however. Two participants believed HCP FC training to be unnecessary and ineffective at increasing FC promotion to service users; "I doubt you'll get much interest in them even though if I'm honest." (age 48, speciality doctor in sexual health). Thus, the perception that HCP training would increase FC uptake was not unanimous. 


\section{Discussion}

The present study used qualitative interview methods to investigate what HCPs perceived to be barriers and facilitators to FC uptake in the UK. Barriers to FC uptake included acceptability, device limitations and insertion difficulties, lack of education and public awareness, cost, and availability. Facilitators to FC uptake included education, promotion, and $\mathrm{HCP}$ training. Overall, there were no specific differences in the responses when comparing HCP role, gender, or age. Nevertheless, the authors believe that future quantitative studies would be able to explore these patterns.

Participants in the present study believed FC acceptability amongst the general population to be low, with women not perceiving the FC as a viable barrier method. Early studies of worldwide FC acceptability reported high rates of acceptability ranging from $37 \%$ to $96 \%$ (22), with later research demonstrating the highest acceptability rates in African settings $(23,24)$ and Asian settings. (25) Studies investigating FC acceptability rates in Western populations have been scarce, with the majority of evidence coming from FC intervention trials that have found higher post-intervention levels of acceptability and actual FC use in heterosexual couples in the United States $(26,27)$, and Spain. (28) However, a large number of HCPs in our study still believed that the FC would be unacceptable to women, a factor that might prevent HCPs from even broaching the topic in consultations.

Issues with the FC as a physical device and insertion practices were thought to be another major barrier to FC uptake in the UK. Many HCPs expressed the view that the device was visually unaesthetic and audibly off-putting, attitudes that have been reported by participants in actual-use randomized trials (29). The FC was also thought to be more difficult to apply than a MC due to issues with inserting the device internally. Indeed, some studies have found that the proportion of users experiencing FC insertion difficulty is as large as 30-55\% (30), leading to inconsistent use (31). However, HCPs in the present study suggested that education interventions which include 
demonstrations might facilitate FC uptake by improving insertion skill. Artz et al., for example, in a study that evaluated a STI clinic-based intervention, found that with practice and repeated use, difficulty with FC insertion dropped from $25 \%$ to $3 \%$. (32) Findings from the present study combined with the existing evidence suggest the importance of skills training in overcoming insertion barriers.

Furthermore, FC availability in the UK remains low, and no widespread distribution schemes currently exist. This is in stark contrast to sustained MC distribution schemes, such as the C-Card, in which holders are entitled to a range of free MCs from most pharmacies and healthcare clinics (33). Researchers have suggested that availability could increase demand considerably (32), yet there have been no attempts to increase the supply of the product in the UK.

Cost and affordability of the FC were also perceived as barriers to FC uptake. Price as a barrier to sustained FC use has been cited in almost every article on the FC from a public health perspective (14), and the higher price of the FC (compared to the MC) "continues to plague largescale national female condom programs" (26, p.123). Even when publicly funded healthcare agencies such as the NHS provide free FCs, they are often in much shorter supply than MCs, as was noted by HCPs in the present study. Without a regular supply of free FCs, there is unlikely to be a change in FC uptake; price and affordability represent enduring issues that threaten the FC as a viable method.

Despite identifying barriers to FC uptake, HCPs in the present study believed steps can be taken to facilitate improved FC attitude and uptake. These included healthcare (e.g. national sexual health schemes) and commercial campaigns (e.g. with high street chains such as Ann Summers). Sexual health promotion campaigns in Africa have been successful at improving attitudes towards FCs. (34)

Simply calling for the promotion of FCs is not enough, however, and it is important to consider exactly what is being promoted and who is being targeted. In our study, promotion of the FC was often mentioned alongside condom use negotiation as a tool that allows women to assume control over their sexual and reproductive health. The FC has been touted as an object of women's 
empowerment by many in the field, but this has yet to translate into FC promotional or marketing campaigns. (26) Increasing the image of the FC as an important tool for women's sexual and reproductive health could encourage HCPs to promote it as much as it may encourage new users to try the device.

\section{Limitations}

There are several limitations to the present study. Firstly, due to high workloads, HCPs represent a population that is generally more difficult to recruit and so snowball sampling was used to enhance recruitment. Oversampling of a particular network of HCPs may lead to bias based on extraneous factors (e.g., local campaigns, political views) and as such we cannot generalize the findings from our sample to all HCPs in the UK.

Another limitation is that telephone interviews also omit some information that adds to the contextual detail of an interview, such as participant body language. Finally, female HCPs made up the majority of the sample, with a resultant lack of a male HCP perspective on the FC, a research gap that has been highlighted as problematic in other studies (35).

\section{Implications}

The present study is the first to explore barriers and facilitators to FC use in the UK from an HCP perspective and the findings have several implications for future efforts to improve FC uptake. Firstly, findings suggest a need for increased FC education and training interventions for both potential users and HCPs. For the user, educational interventions could take place in school/ healthcare settings that would include applying FCs on anatomical models to allow users to gain confidence in fitting and using the device. For the HCP, education consisting of in-clinic workshops and seminars should be implemented to encourage FC promotion behaviour. This may allow HCPs to become more confident in promoting the device to service users.

Lastly, there is a need for quantitative data regarding FC user acceptability in the UK. Data on FC acceptability and uptake in the UK are sparse and largely outdated, with the new designs and FC 
types available. New UK FC data would serve to reignite the conversation surrounding FCs and also serve as an evidence base to be included in HCP FC training programmes.

\section{Conclusion}

The FC is an important yet underused and under-promoted product in the field of sexual health. HCPs are well-positioned to advocate the FC as service users often turn to them for advice on contraception and STI prevention decision making. HCP's knowledge and perceptions of FCs may therefore have a significant effect on overall FC uptake. Interventions to improve FC uptake should consider the knowledge and skills of the user but prioritise the influence of the HCP; HCPs are likely the catalysts to successful FC efforts. 


\section{References}

1. Public Health England. Sexually transmitted infections and screening for Chlamydia in England, 2017. Health Protection report. London: Public Health England, (2018a). Available from: https://www.gov.uk/government/statistics/sexually-transmitted-infections-stis-annualdata-tables [Accessed 25th March 2020]

2. Public Health England. Health matters: Reproductive health and pregnancy planning. London: Public Health England (2018b). Available from:

https://www.gov.uk/government/publications/health-matters-reproductive-health-andpregnancy-planning/health-matters-reproductive-health-and-pregnancy-planning [Accessed 25th March 2020]

3. Development Economics. Unprotected nation: The financial and economic impacts of restricted contraceptive and sexual health services. London: Society of Sexual health Advisors, (2013) 16. Retrieved from: http://ssha.info/wp-content/uploads/UnprotectedNation.pdf [Accessed 23rd March 2020]

4. Oldson L. Sexual Health News - Sexually Transmitted Diseases. Sexual Health. 2013. Available from: https://www.sexualhealth.com/why-women-are-more-at-risk-for-stds-than-

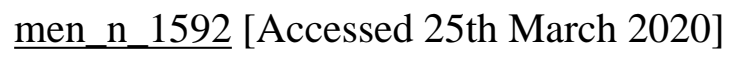

5. Kimport K. More than a physical burden: Women's mental and emotional work in preventing pregnancy. J Sex Res. 2018;55(9):1096-105. Available from: doi: $10.1080 / 00224499.2017 .1311834$

6. Webster R, Michie S, Estcourt C, Gerressu M, Bailey JV, MenSS Trial Group. Increasing condom use in heterosexual men: development of a theory-based interactive digital intervention. Transl Behav Med. 2016;6(3):418-27. doi: 10.1007/s13142-015-0338-8

7. East L, Jackson D, O'Brien L, Peters K. Condom negotiation: Experiences of sexually active young women. J Adv Nurs. 2011;1:77-85. doi: 10.1111/j.1365-2648.2010.05451.x 
8. Gomez AM, Fuentes L, Allina A. Women or LARC first? Reproductive autonomy and the promotion of long-acting reversible contraceptive methods. Perspect Sex Repro H. 2014;46(3):171-5.

9. Parks C, Peipert JF. Eliminating health disparities in unintended pregnancy with long-acting reversible contraception (LARC). Am J Obstet Gynecol 2016;214(6):681-8. doi: 10.1016/j.ajog.2016.02.017

10. Blanc AK. The effect of power in sexual relationships on sexual and reproductive health: an examination of the evidence. Stud Family Plann 2001;32(3):189-213.

11. Gallo MF, Kilbourne-Brook M, Coffey PS. A review of the effectiveness and acceptability of the female condom for dual protection. Sex Health. 2012;9(1):18-26. Available from: doi: $10.1071 /$ SH11037

12. Health Link BC. Barrier Methods of Birth Control. Available from: https://www.healthlinkbc.ca/health-topics/zm2456 [Accessed 18 February 2020].

13. Leeper MA, Conrardy M. Preliminary evaluation of REALITY, a condom for women to wear. Adv Contracept. 1989;5(4):229-35. Available from: doi: 10.1007/ BF01890894

14. Peters A, Jansen W, van Driel F. The female condom: the international denial of a strong potential. Reprod Health Matter 2010;18(35):119-28. doi: 10.1016/S0968-8080(10)35499-1

15. Mantell JE, West BS, Sue K, Hoffman S, Exner TM, Kelvin E, Stein ZA. Health care providers: A missing link in understanding acceptability of the female condom. AIDS Educ Prev. 2011;23(1):65-77. doi: 10.1521/aeap.2011.23.1.65

16. Ananga MK, Kugbey N, Akporlu M., Asante KO. Knowledge, acceptance and utilisation of the female condom among women of reproductive age in Ghana. Contracep Rep Med. 2017; 2:15. doi:10.1186/s40834-017-0042-9 
17. Bowling J, Dodge B, Bindra N, Dave B, Sharma R, Sundarraman V, Thirupathur Dharuman S, Herbenick D. Female condom acceptability in urban India: Examining the role of sexual pleasure. J Health Psychol. 2018;23(2):218-28. doi: 10.1177/1359105317745963

18. Lamvu G, Steiner MJ, Condon S, Hartmann K. Consistency between most important reasons for using contraception and current method used: the influence of health care providers. Contraception. 2006 Apr 1;73 (4):399-403. doi: 10.1016/j.contraception.2005.10.007

19. Biernacki P, Waldorf D. Snowball sampling: Problems and techniques of chain referral sampling. Sociol Method Res. 1981;10(2):141-63. Available from: doi: 10.111/0433449983/A-T1

20. Noy C. Sampling knowledge: The hermeneutics of snowball sampling in qualitative research. Int J Soc Res Method. 2008;11(4):327-44. Available from: doi: $10.1080 / 13645570701401305$

21. Braun V, Clarke V. Using thematic analysis in psychology. Qual Res Psychol. 2006;3(2):77101. Available from: doi: 10.1191/1478088706qp063oa

22. Cecil H, Perry MJ, Seal DW, Pinkerton SD. The female condom: What we have learned thus far. AIDS Behav. 1998;2(3):241-56. Available from: doi: 10.1023/A:1022141918771

23. Mantell JE, Scheepers E, Karim QA. Introducing the female condom through the public health sector: experiences from South Africa. AIDS Care. 2000;12(5):589-601. Available from: doi: 10.1080/095401200750003770

24. Beksinska ME, Rees VH, McIntyre JA, Wilkinson D. Acceptability of the female condom in different groups of women in South Africa- A multicentred study to inform the national female condom introductory strategy. S Afr Med J. 2001;91(8).

25. Wang Y, Liao SS, Weeks MR, Jiang JM, Abbott M, Zhou YJ, He B, Liu W, Mosack KE. Acceptability of hypothetical microbicides among women in sex establishments in rural 
areas in Southern China. Sex Transm Dis. 2008;35(1):102. Available from: doi: 10.1097/OLQ.0b013e31814b8546

26. Hoffman S, Mantell J, Exner T, Stein Z. The future of the female condom. Perspect Sex Repro H. 2004;36(3):120-6. Available from: doi: 10.1363/psrh.36.120.04

27. Witte SS, El $\square$ Bassel N, Gilbert L, Wu E, Chang M, Hill J. Promoting female condom use to heterosexual couples: findings from a randomized clinical trial. Perspect Sex Repro H. 2006;38(3):148-54. Available from: doi: 10.7916/D8795MRH

28. Fernández ML, Garrido JM, Castro YR, María A, Mangana N, Fernández MV, Foltz ML. Assessing female condom acceptability among heterosexual Spanish couples. Eur J Contracep Repr. 2008;13(3):255-63. Available from: doi: 10.1080/13625180802075232

29. Kulczycki A, Kim DJ, Duerr A, Jamieson DJ, Macaluso M. The acceptability of the female and male condom: a randomized crossover trial. Perspect Sex Repro H. 2004;36(3):114-9. Available from: doi: 10.1363/3611404

30. Hoffman S, Exner TM, Leu CS, Ehrhardt AA, Stein Z. Female-condom use in a genderspecific family planning clinic trial. Am J Public Health. 2003;93(11):1897-903. Available from: doi: 10.2105/AJPH.93.11.1897

31. Sapire KE. The female condom (Femidom)-a study of user acceptability. S Afr Med J. $1995 ; 85(10)$.

32. Artz L, Macaluso M, Brill I, Kelaghan J, Austin H, Fleenor M, Robey L, Hook 3rd EW. Effectiveness of an intervention promoting the female condom to patients at sexually transmitted disease clinics. Am J Public Health. 2000;90(2):237. Available from: doi: 10.2105/AJPH.90.2.237

33. Public Health England. Condom distribution schemes in England 2015/2016: A survey of English sexual health commissioners. London: Public Health England (2017) 35, CM 2017343. Available from: 
https://assets.publishing.service.gov.uk/government/uploads/system/uploads/attachment_data /file/666306/Condom_Distribution_Schemes_in_England_2015.pdf

34. Agha S, Van Rossem R. Impact of mass media campaigns on intentions to use the female condom in Tanzania. Int Fam Plan Perspec. 2002;28(3):151-8.

35. Moore L, Beksinska M, Rumphs A, Festin M, Gollub EL. Knowledge, attitudes, practices and behaviors associated with female condoms in developing countries: A scoping review. Open Access J Contracept. 2015;6:125. 
Table 1: Interview Topic Guide.

\begin{tabular}{|c|c|}
\hline No. & Telephone Interview questions \\
\hline 1 & What is your age, gender, and professional role? \\
\hline 2 & $\begin{array}{l}\text { Can you tell me about your professional background and } \\
\text { work history? }\end{array}$ \\
\hline 3 & Can you tell me what you know about the female condom? \\
\hline 4 & $\begin{array}{l}\text { To what extent do you think that female condoms are } \\
\text { effective? }\end{array}$ \\
\hline 5 & $\begin{array}{l}\text { Who do you believe the female condom should be targeted } \\
\text { towards? }\end{array}$ \\
\hline 6 & $\begin{array}{l}\text { What are the main challenges to the national distribution of } \\
\text { female condoms? }\end{array}$ \\
\hline 7 & $\begin{array}{l}\text { What would facilitate a change in policy to offer female } \\
\text { condoms to protect women against STIs? }\end{array}$ \\
\hline 8 & $\begin{array}{l}\text { Would you recommend the female condom to a client, and } \\
\text { can you explain the reason for your answer? }\end{array}$ \\
\hline
\end{tabular}


Table 2: Coding Manual for Thematic Analysis.

\begin{tabular}{|c|c|c|c|}
\hline Major theme & Sub-theme & Description & Illustrative Quote \\
\hline \multirow[t]{2}{*}{$\begin{array}{l}\text { HCP } \\
\text { knowledge and } \\
\text { attitudes }\end{array}$} & $\begin{array}{l}\text { Personal } \\
\text { knowledge and } \\
\text { attitudes }\end{array}$ & $\begin{array}{l}\text { General knowledge possessed } \\
\text { about the FC and attitudes, } \\
\text { beliefs, and perceptions } \\
\text { towards the FC }\end{array}$ & $\begin{array}{l}\text { "I don't know an awful lot..." } \\
\text { "Erm, I think it's quite old fashioned } \\
\text { and it's just quite, I don't know, it's } \\
\text { quite a bit of a fad compared to like a } \\
\text { male condom." }\end{array}$ \\
\hline & $\begin{array}{l}\text { Perceived } \\
\text { effectiveness of } \\
\text { the FC }\end{array}$ & $\begin{array}{l}\text { Specific knowledge } \\
\text { possessed by the HCP } \\
\text { regarding the effectiveness of } \\
\text { the FC as a medical device }\end{array}$ & $\begin{array}{l}\text { "I think they're of similar efficacy as } \\
\text { the male condom..." }\end{array}$ \\
\hline \multirow[t]{5}{*}{$\begin{array}{l}\text { Perceived } \\
\text { barriers to FC } \\
\text { uptake }\end{array}$} & Acceptability & $\begin{array}{l}\text { The belief that low user } \\
\text { acceptability acts as a barrier } \\
\text { to FC uptake }\end{array}$ & $\begin{array}{l}\text { "...the user is not that interested in } \\
\text { them" } \\
\text { "...I'll only offer it to people who I } \\
\text { think would benefit from it, but most } \\
\text { are like "yeah, no, don't want it" }\end{array}$ \\
\hline & $\begin{array}{l}\text { Device limitations } \\
\text { and insertion } \\
\text { difficulties }\end{array}$ & $\begin{array}{l}\text { The beliefs that the FC } \\
\text { product itself and issues } \\
\text { applying the product for use } \\
\text { act as barriers to FC uptake }\end{array}$ & $\begin{array}{l}\text { "the feedback I've got off patients is } \\
\text { that it's like having sex with a crisp } \\
\text { packet..." } \\
\text { "I think they find it a lot more fiddly } \\
\text { than a [male] condom to put on..." }\end{array}$ \\
\hline & $\begin{array}{l}\text { Lack of public } \\
\text { awareness and } \\
\text { education }\end{array}$ & $\begin{array}{l}\text { The beliefs that a lack of } \\
\text { public awareness of the FC } \\
\text { and a lack of FC education } \\
\text { programs act as barriers to FC } \\
\text { uptake }\end{array}$ & $\begin{array}{l}\text { "I'm not sure, I think a lot of women } \\
\text { have no idea about them, I think that } \\
\text { there's probably a lack of education } \\
\text { about them..." } \\
\text { "...in fact I don't think a lot of people } \\
\text { are aware of them actually." }\end{array}$ \\
\hline & Availability & $\begin{array}{l}\text { The belief that a lack of } \\
\text { availability acts as a barrier to } \\
\text { FC uptake }\end{array}$ & $\begin{array}{l}\text { "they're not very readily available and } \\
\text { never in my practice have I given them } \\
\text { to any patient." }\end{array}$ \\
\hline & Cost & $\begin{array}{l}\text { The belief that pricing of the } \\
\text { FC acts as a barrier to uptake }\end{array}$ & $\begin{array}{l}\text { "...they are more expensive to } \\
\text { produce too." }\end{array}$ \\
\hline $\begin{array}{l}\text { Perceived } \\
\text { facilitators to } \\
\text { FC uptake }\end{array}$ & Education & $\begin{array}{l}\text { The perception that FC } \\
\text { education programmes could } \\
\text { facilitate an increase in FC } \\
\text { uptake }\end{array}$ & $\begin{array}{l}\text { "I think erm, from a healthcare } \\
\text { awareness point of view education } \\
\text { would be really useful, and actually } \\
\text { somebody demonstrating it, exactly } \\
\text { how to put it on and everything like } \\
\text { that..." } \\
\text { "...so I think they would need, they } \\
\text { would need education on how to use }\end{array}$ \\
\hline
\end{tabular}




\begin{tabular}{|l|l|l|l|}
\hline & Promotion & $\begin{array}{l}\text { The perception that increased } \\
\text { FC promotion could facilitate } \\
\text { uptake }\end{array}$ & $\begin{array}{l}\text { them and you know, like a, like a male } \\
\text { condom really..." } \\
\text { promotion in general, yeah, make } \\
\text { people a bit more aware and then it's } \\
\text { their choice at the end of the day if } \\
\text { they want to use them or not isn't it." }\end{array}$ \\
\hline HCP training & $\begin{array}{l}\text { The perception that specific } \\
\text { FC training programmes for } \\
\text { active HCPs could facilitate } \\
\text { uptake }\end{array}$ & $\begin{array}{l}\text { "..maybe re-training staff, so they are } \\
\text { comfortable and confident to give } \\
\text { them out." } \\
\text { "Erm, I think, to start off with you } \\
\text { need to train the trainers, so getting the } \\
\text { staff onboard, umm, and then I would } \\
\text { say, umm, that's something, they can } \\
\text { they be talking to patients about using } \\
\text { them more." }\end{array}$ \\
\hline
\end{tabular}

